\title{
Article \\ Electrospun Membranes as a Porous Barrier for Molecular Transport: Membrane Characterization and Release Assessment
}

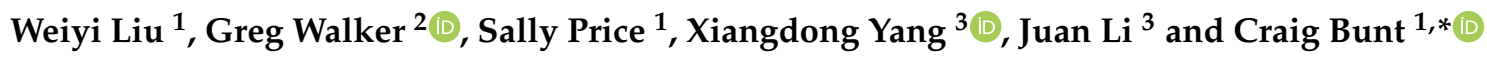 \\ 1 Faculty of Agriculture and Life Sciences, Lincoln University, Lincoln 7608, New Zealand; \\ weiyi.liu@lincoln.ac.nz (W.L.); sally.price@lincoln.ac.nz (S.P.) \\ 2 School of Pharmacy, University of Otago, Dunedin 9054, New Zealand; greg.walker@otago.ac.nz \\ 3 Institute of Agricultural Resources and Regional Planning, Chinese Academy of Agricultural Sciences/Key \\ Laboratory of Plant Nutrition and Fertiliser, Ministry of Agriculture and Rural Affairs, Beijing 100081, China; \\ yangxiangdong@caas.cn (X.Y.); lijuan02@caas.cn (J.L.) \\ * Correspondence: craig.bunt@lincoln.ac.nz
}

Citation: Liu, W.; Walker, G.; Price,

S.; Yang, X.; Li, J.; Bunt, C.

Electrospun Membranes as a Porous Barrier for Molecular Transport: Membrane Characterization and Release Assessment. Pharmaceutics 2021, 13, 916. https://doi.org/ 10.3390/pharmaceutics13060916

Academic Editor: Duncan Craig

Received: 17 May 2021

Accepted: 18 June 2021

Published: 21 June 2021

Publisher's Note: MDPI stays neutral with regard to jurisdictional claims in published maps and institutional affiliations.

Copyright: (C) 2021 by the authors. Licensee MDPI, Basel, Switzerland. This article is an open access article distributed under the terms and conditions of the Creative Commons Attribution (CC BY) license (https:// creativecommons.org/licenses/by/ $4.0 /)$.
Abstract: Electrospun nanofibers have been extensively studied for encapsulated drugs releasing from the inside of the fiber matrix, but have been barely looked at for their potential to control release as a semi-permeable membrane. This study investigated molecular transport behaviors across nanofiber membranes with different micro-structure sizes and compositions. Four types of membranes were made by $5 \%$ and $10 \%$ poly ( $\varepsilon$-caprolactone) (PCL) solutions electro-spun with or without $50 \mathrm{~nm}$ calcium carbonate $\left(\mathrm{CaCO}_{3}\right)$ nanoparticles. The membranes were tested for thickness, fiber diameter, pore size, porosity, tensile strength and elongation, contact angle of water and their impacts on molecular transport behaviors. The presence of the $\mathrm{CaCO}_{3}$ nanoparticles made the $5 \%$ membranes stronger and stiffer but the $10 \%$ membranes weaker and less stiff due to the different (covering or embedded) locations of the nanoparticles with the corresponding fibers. Solute transport studies using caffeine as the model drug found the $5 \%$ membranes further retarded release from the $10 \%$ membranes, regardless of only half the amount of material being used for synthesis. The addition of $\mathrm{CaCO}_{3}$ nanoparticles aided the water permeation process and accelerated initial transports. The difference in release profiles between $5 \%$ and $10 \%$ membranes suggests different release mechanisms, with membrane-permeability dominated release for 5\% PCL membranes and solute-concentration-gradient dominated release for $10 \%$ PCL membranes.

Keywords: electrospinning; semi-permeable membrane; membrane characterization; controlled release; nanoparticles; release mechanisms

\section{Introduction}

Electrospinning is a broadly used technique spinning either polymer solutions or melted polymers onto an earthed collector in a zone affected by strong electric fields. The membrane produced consists of numerous nano- or micro-scaled fibers interweaved and overlapped with each other to form fibrous and porous structures inside [1]. This technique has been shown to have many advantages such as producing nanofibers continuously and being easy to manipulate. It can be used with many types of polymers and suitable for various practical purposes. All these merits have made it popular over the last three decades. The membranes produced by electrospinning have been used in many fields including tissue engineering, filtration, biosensors, water-repellent clothing, energy generation, immobilization of enzymes, affinity membrane, cosmetics and biomedical applications [1-3].

Drug delivery is a sub-branch of biomedical application. A large number of studies have worked on incorporating drugs into polymer nanofibers and releasing the drugs from the inside of the nanofiber matrix. Loh et al. [4] created a thermoresponsive nanofiber 
formulation for controlled release of the protein bovine serum albumins (BSA) by electrospinning a mixture of a poly (ester urethane)s solution with the addition of the protein. The release rate of the protein can be controlled by altering the temperature in release environments. Yohe et al. [5] incorporated 7-ethyl-10-hydroxycamptothecin (SN-38) into a super-hydrophobic nanofiber membrane (water contact angle $>150^{\circ}$ ) made by poly ( $\varepsilon$-caprolactone) (PCL) and poly (glycerol monostearate-co- $\varepsilon$-caprolactone) and found that the air trapped in the membrane acted as a natural barrier, further retarding drug release from conventional hydrophobic membranes.

Although the research to incorporate drugs into fiber structures is well established, very few researchers have investigated controlling their release using nanofiber membranes as a physical barrier. To our knowledge, only three articles have published results in this area. Falde et al. [6] used the same super-hydrophobic nanofiber membrane made in [5] but employed it as a barrier layer to control release. It has been found the air trapped in the membrane functioned as good as when it was used in matrix systems to retard release. Scaffaro et al. [7] sandwiched a carvacrol (CRV) loaded polylactic acid (PLA) film with PLA nanofiber membranes of different thicknesses. Their results showed a diminished burst release of CRV with the increase of membrane thickness. The release of CRV across the PLA membranes has been found dominated by a diffusion mechanism. Fouling is a common phenomenon for microfiltration. It describes a situation where the flux of molecules is reduced during filtration due to the blockage of electrospun membrane pores caused by the interaction between foulants and the membrane [8,9]. Zhao et al. [10] found the fouling effect also existed in molecular transport processes. They investigated the impact of the fouling on the release of a protein BSA across polyacrylonitrile (PAN) nanofiber membranes using side-by-side diffusion chambers and observed a significantly lower diffusion coefficient produced for electrospun fibrous membranes than those for other fibrous media when the ratio of the protein size and pore size reached a certain value.

We obtained inspiration to control molecular release across nanofiber membranes from the above studies. If the thickness, hydrophobicity and molecular interaction of fibers and transporting molecules can be a tool to impact release, would the fiber diameter and pore size be another tool to manipulate the release? It has been well reported that the fiber diameter produced by electrospinning can be reduced by decreasing the polymer concentration used for synthesis process [11-13]. It was also reported in microfiltration that the flux of molecules can be altered by changing the microstructure of the nanofiber membranes such as the fiber diameter and porosity [14]. With these research tips, we conducted experiments on $5 \%$ and $10 \%$ PCL nanofiber membranes and hypothesized that the $5 \%$ membranes with thinner fibers and smaller pores would decrease release rates from the $10 \%$ membranes due to lower permeability. Nanoparticles (NPs) were another tool used in this study to manipulate the release rate. Many studies have found that by adding hydrophilic fillers, the water permeability of polymer membranes can be increased [15-17]. It was curious to understand whether the hydrophilic NPs can be used to accelerate the release rate of electrospun membranes. For this purpose, commercial calcium carbonate $\left(\mathrm{CaCO}_{3}\right) \mathrm{NPs}$ with a diameter of $50 \mathrm{~nm}$ were electro-spun with $5 \%$ and $10 \%$ PCL solutions to make nanofiber membranes containing hydrophilic fillers.

It has been found in this study that the NPs impacted the mechanical strength and elasticity of the membranes and made the 5\% PCL membranes stronger and stiffer but the $10 \%$ PCL membranes weaker and less stiff. After eliminating the impacts of membrane thickness, hydrophobicity and the fouling phenomenon, it has been found that the $5 \%$ membranes can further retard release from the $10 \%$ membranes due to smaller pore size. The difference between accelerated and decelerated release styles appeared on $5 \%$ and $10 \%$ membranes proposed different working release mechanisms, with membrane-permeability dominated release for $5 \%$ membrane and solute-concentration-gradient dominated release for $10 \%$ membrane. The additions of $\mathrm{CaCO}_{3} \mathrm{NPs}$ were not able to change the overall styles of the release but increased the initial release rate. 


\section{Materials and Methods}

\subsection{Materials}

Poly ( $\varepsilon$-caprolactone) (PCL) (MW 80,000) and caffeine (98.5\% purity) were purchased from Sigma-Aldrich, Auckland, New Zealand. Dichloromethane (HPLC grade) was obtained from Fisher Scientific, Loughborough, UK. Methanol (laboratory-grade) was purchased from Thermo Fisher Scientific, Auckland, New Zealand. Calcium carbonate $\left(\mathrm{CaCO}_{3}\right)$ nanoparticles with a diameter of $50 \mathrm{~nm}$ and a purity of $98 \%$ were acquired from US Research Nanomaterials, Houston, TX, USA.

\subsection{Membrane Preparation by Electrospinning}

Poly ( $\varepsilon$-caprolactone) nanofiber membranes were fabricated by adding $0.4 \mathrm{~g}$ PCL, $0.8 \mathrm{~g}$ PCL, $0.38 \mathrm{~g}$ PCL with $0.02 \mathrm{~g} \mathrm{CaCO}_{3}$ nanoparticles and $0.76 \mathrm{~g}$ PCL with $0.04 \mathrm{~g}$ $\mathrm{CaCO}_{3}$ nanoparticles, respectively, into an $8 \mathrm{~mL}$ solvent consisting of dichloromethane and methanol in a ratio of $3: 1$ to make $5 \%, 10 \%, 5 \%$ with $5 \% \mathrm{CaCO}_{3} \mathrm{NPs}$ (to the weight of the solute), and $10 \%$ with $5 \% \mathrm{CaCO}_{3}$ NPs (to the weight of the solute) membranes. Samples were stirred for $1 \mathrm{~h}$ until a homogenous solution or dispersion was obtained before being transferred to a $5 \mathrm{~mL}$ syringe $\left(\mathrm{TERUMO}^{\circledR}\right)$. A voltage of $20 \mathrm{kV}$ supplied by a high voltage generator (DEL HVPS INST $23030 \mathrm{KV}$, Spellman ${ }^{\circledR}$ ) with a solution feed rate of $4 \mathrm{~mL} \mathrm{~h}^{-1}$ and a flat end (23 gauge, TERUMO ${ }^{\circledR}$ ) needle-to-collector distance of $20 \mathrm{~cm}$ was employed as the conditions for electro-spinning over a period of $1 \mathrm{~h}$. All the samples were produced at room temperature with a humidity range from $40 \%$ to $60 \%$. An earthed disc-shaped collector with a diameter of $10 \mathrm{~cm}$, covered with aluminum foil (mono ${ }^{\circledR}$ ) was rotated at $30 \mathrm{rpm}$ during nanofiber collection. A set of images and photos illustrating the membrane preparation process is displayed in Figure 1.
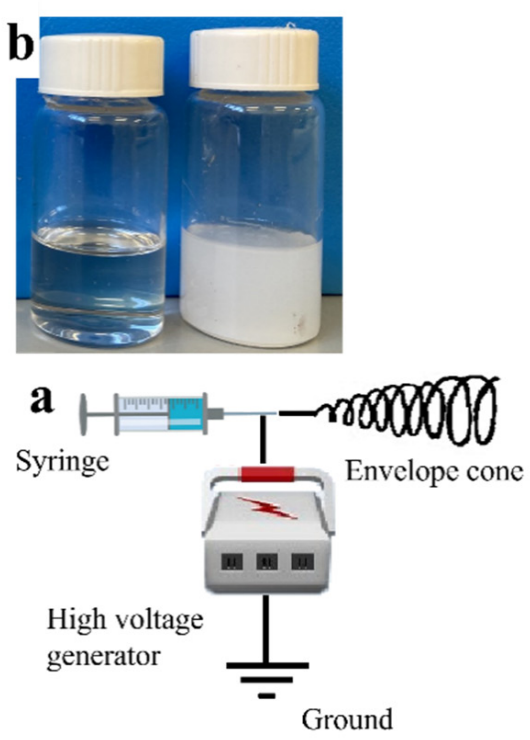

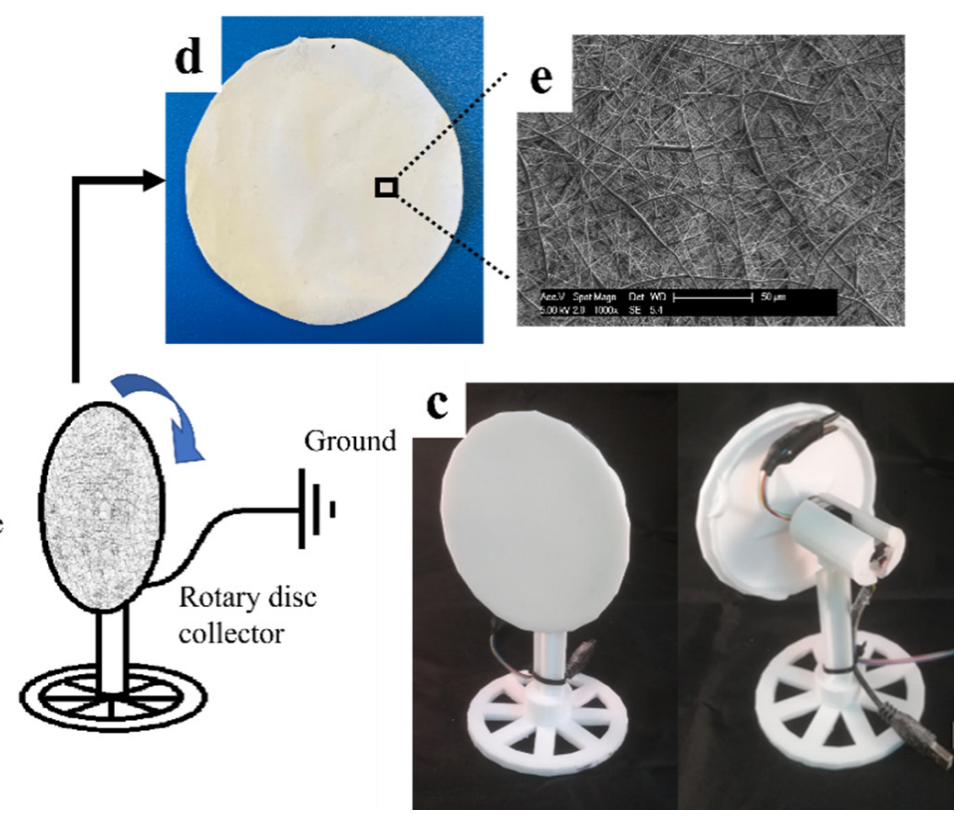

Figure 1. Schematic illustration of (a) the electrospinning process, (b) a 10\% Poly ( $\varepsilon$-caprolactone) (PCL) solution (left bottle) and a $10 \%$ PCL solution with calcium carbonate $\left(\mathrm{CaCO}_{3}\right)$ nanoparticles (NPs) uniformly dispersed (right bottle) in DCM: Methanol = 3:1, (c) rotary disc collector used to collect nanofiber membranes, (d) a piece of 10\% nanofiber membrane, (e) Scanning electron microscopy (SEM) image of a $10 \%$ membrane sample.

\subsection{Thickness Measurement}

The thickness of nanofiber membranes was measured using micrometer calipers (mi004, Metalworking, Fuzhou, China). To minimize the compression impact of the measuring rods of the caliper, the membranes were folded twice before measurement. Three points being $1 \mathrm{~cm}, 2.5 \mathrm{~cm}$ and $4 \mathrm{~cm}$ away from the center of the circular membranes 
were measured. The thicknesses showed in this study were the averages of the measurements divided by 4 . A detailed explanation of this method is available to view in the Supplementary File.

\subsection{Fiber Morphology and Membrane Characterization}

Nanofiber membrane samples were collected minimizing physical changes to its structure and stored at ambient room temperature. Scanning electron microscopy (SEM, Zeiss Sigma VP FEG/ Phillips XL30 FEG) was used to study the surface morphology of the membranes. The side of the membrane in contact with the air and collecting fibers in the spinning process was placed facing upward on a stub and coated with a $20 \mathrm{~nm}$ platinum layer before imaging with the SEM. Each sample was tested in $5000 \times$ and $20,000 \times$ magnifications for the overall morphology and the appearance of the $\mathrm{CaCO}_{3}$ NPs. Fiber diameter and pore size were measured using ImageJ (Fiji, National Institute of Mental Health, Bethesda, MD, US) on the SEM images. The average of 60 diameters and 100 successive pore areas were measured to obtain the values for fiber diameter and pore size. The mass of each $10 \mathrm{~cm}$ diameter samples was weighed and calculated with their thicknesses to obtain the membrane densities. The porosity of the membranes was calculated using the Equation (1) [18]:

$$
\text { Porosity }(\%)=\left(1-\frac{\rho}{\rho_{0}}\right) \times 100 \%
$$

where:

$\rho=$ the density of electrospun PCL membrane;

$\rho_{0}=$ the density of bulk PCL polymer $\left(1.14 \mathrm{~g} / \mathrm{cm}^{3}\right)$.

\subsection{Tensile Strength and Elongation}

A puncture test was carried out to measure the tensile properties of the nanofiber membranes. In the measurement, membrane samples were fixed in a ring clamp having a $2 \mathrm{~cm}$ diameter hole. The clamp loaded with the membrane samples was placed on the testing stage of a TA.XT plus Texture Analyzer (Stable Micro Systems) with the surface of the membranes facing up. A testing probe $5 \mathrm{P} / \mathrm{S}$ and $5 \mathrm{~kg}$ load cell were used to punch the membranes in the hole from the top at a pre-test speed of $2 \mathrm{~m} \mathrm{~ms}^{-1}$ and test speed $0.5 \mathrm{~m} \mathrm{~ms}^{-1}$ until the samples were ruptured. The trigger force to start the measurement was $1 \mathrm{~g}$. During the process, force and probe moving distance were recorded to draw the stress-strain curves of the membranes. Elastic property was assessed using the Young's Modulus calculated from the slope of the linear elastic region of the curves. The equations to calculate these parameters are showed below $[19,20]$ :

$$
\begin{gathered}
\text { Stress }(\mathrm{MPa})=F / A \\
A\left(\mathrm{~m}^{2}\right)=2 r h \\
\text { Strain }(\%)=\frac{\sqrt{r^{2}+d^{2}}-r}{r} \times 100 \% \\
\text { Young's Modulus }(\mathrm{MPa})=\text { Stress } / \text { Strain }
\end{gathered}
$$

where:

$F=$ the force required to deform the membranes $(\mathrm{N})$;

$A=$ the sectional area of nanofiber membrane $\left(\mathrm{m}^{2}\right)$;

$r=$ the radius of the tested membranes mounted on the clumping ring $(\mathrm{cm})$;

$h=$ the thickness of the tested membranes (m);

$d=$ the displacement of membranes being punctured $(\mathrm{cm})$. 


\subsection{Water Contact Angle}

Water contact angles were measured as described by Williamsa et al. [21] using the ImageJ (version 1.46, National Institute of Mental Health, Bethesda, MD, USA) plugin DropSnake (version 2.1, Biomedical Imaging Group, Lausanne, Switzerland). To obtain the angle, a $4 \mu \mathrm{L}$ droplet of Reverse osmosis (RO) water was gently pipetted onto the nanofiber samples of which the size is large enough to ensure complete contact between the waterdrop and the membrane samples. A digital microscope (Microscope 2MP Digital $500 \times 8 \mathrm{LED}$, Andonstar, Shenzhen, China) was used to capture the shape of the water drop. The original pictures were then edited into a perfectly horizontal and tidy appearance for the best performance of the measurement. The contact angles used in this study were the averages of left and right angles measured by DropSnake. A schematic diagram for the apparatus arrangement is available to view in the Supplementary File.

\subsection{Solute Transport Experiment}

Solute transport through the nanofiber membranes was assessed using a side-by-side diffusion chamber (CHM3, WORLD PRECISION INSTRUMENTS) consisting of two $1.2 \mathrm{~mL}$ chambers with a $12 \mathrm{~mm}$ orifice. Circular membrane samples (a diameter of $2.5 \mathrm{~cm}$ ) of $5 \%$, $5 \%$ with NPs, $10 \%$ and $10 \%$ with NPs were mounted between the "donor" and "receptor" chamber. RO water $(19 \mathrm{~mL})$ was added to each of the chamber columns followed by $1 \mathrm{~mL}$ of $0.8 \mathrm{mg} / \mathrm{mL}$ caffeine solution added to the "donor" side and $1 \mathrm{~mL}$ of RO water added to the "receptor" side to make up $20 \mathrm{~mL}$ in each column. Samples $(100 \mu \mathrm{L})$ were collected from the top side of both columns after $0.25,0.5,1,2,3,4,5,6,23,24,25,26$, $27,28,29,30,47,48 \mathrm{~h}$ and analyzed for caffeine using a UV/Vis Spectrophotometer at $287 \mathrm{~nm}$ (Multiskan GO, Thermo Scientific ${ }^{\circledR}$, Vantaa, Finland). Absorbances were converted to caffeine concentration by using a standard curve of $0,10,20,30$ and $40 \mu \mathrm{g} / \mathrm{mL}$ caffeine prepared in $100 \mathrm{~mL}$ water. Fisher's least significant difference (LSD) was used to analyze the pairwise differences among the solute concentrations in the "receptor" side for the four types of membranes after $6,23,30$ and $48 \mathrm{~h}$.

\section{Results and Discussion}

\subsection{Nanofiber Morphologies}

The appearances and fiber morphologies of $5 \%$ and $10 \%$ PCL membranes have been investigated in this study. Figure 2a,b illustrates the difference between the two membranes in appearance, with the $5 \%$ membrane exhibiting a softer and more flexible texture than the $10 \%$ membrane. The nanofiber morphologies of the two membranes were observed on SEM. The 5\% PCL solution generated nano-scale fibers (diameter from 0.15 to $0.41 \mu \mathrm{m}$ ) with some micro-beads (waist width from 1.91 to $5.33 \mu \mathrm{m}$ ) connected in-line (Figure 2c,e). This is consistent with the literature reporting that polymer micro-beads were formed in electrospinning process when the concentration of the polymers in spun solutions decreased to a critical value $[3,22]$. The formation of the micro-beads is attributed to a break of entangled polymer chains into fragments before they reach the collector [23]. The $10 \%$ PCL solution, in contrast, created a fiber-only structure in micro-scale (diameter from 0.54 to $2.33 \mu \mathrm{m}$ ) (Figure $2 \mathrm{~d}, \mathrm{f})$. The fibers produced by $5 \%$ PCL solution are narrower than those produced by $10 \%$ PCL solution. It has been well reported that the nanofibers produced by electrospinning enlarge with the increase of polymer concentration used for synthesis [11-13]. 


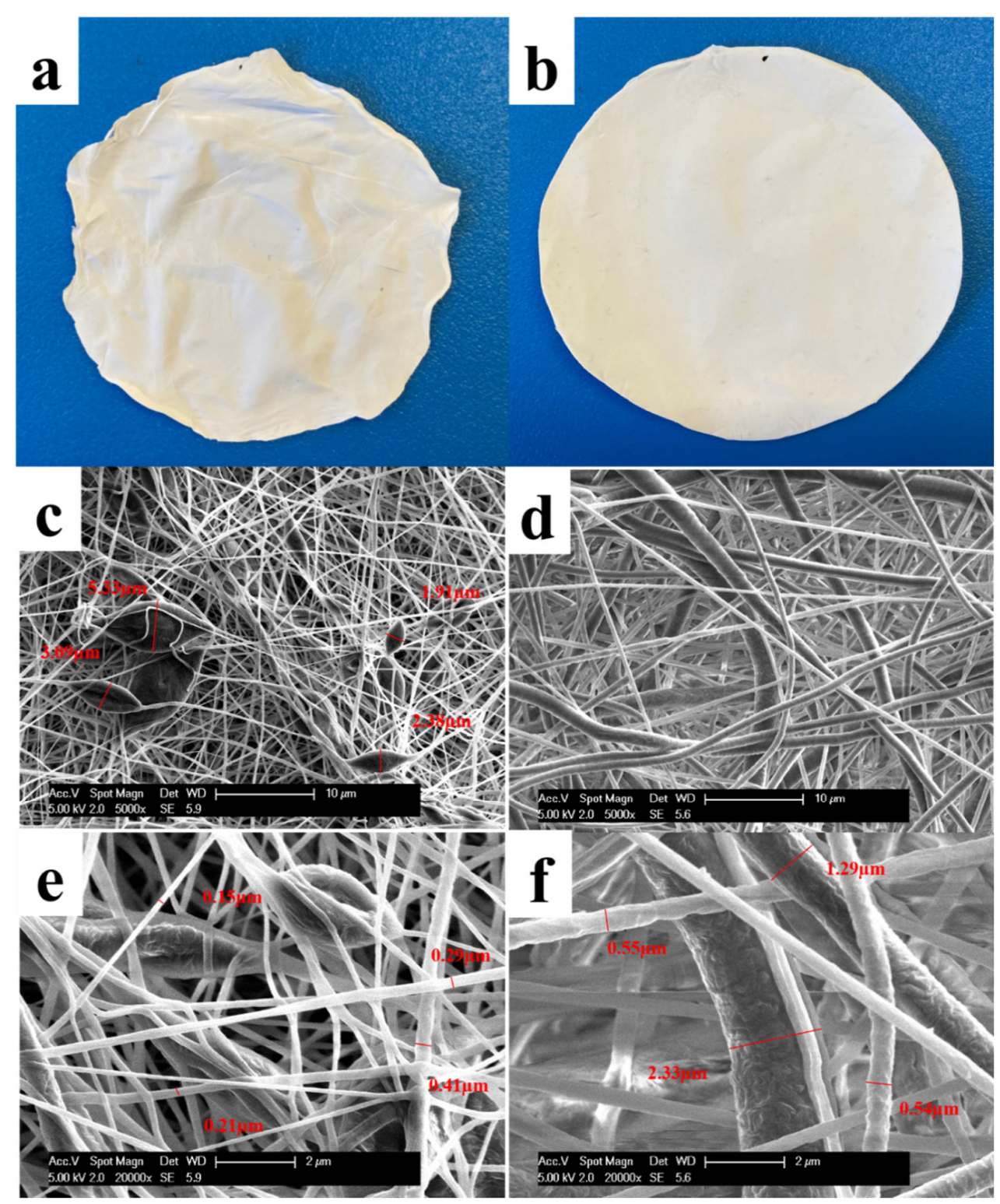

Figure 2. The macroscopic appearances of (a) a 5\% PCL membrane and (b) a 10\% PCL membrane. The SEM images of (c) 5\% PCL nanofibers and micro-beads observed at $5000 \times$ magnification with some of the micro-beads measured for the widths, (d) 10\% PCL nanofibers at $5000 \times$ magnification, (e) 5\% PCL nanofibers and micro-beads at 20,000 $\times$ magnification with some of the fibers measured for the diameters, (f) $10 \%$ PCL nanofibers at 20,000 $\times$ magnification with some of the fibers measured for the diameters.

To evaluate the role of hydrophilic fillers, $5 \% \mathrm{CaCO}_{3} \mathrm{NPs}$ (to the weight of the solute) were electro-spun with $5 \%$ and $10 \%$ PCL solutions at the same spinning conditions. Calcium carbonate NPs were selected for this study as these particles have been widely proved to be feasible to incorporate with hydrophobic polymer fibers such as those made by PCL [24-26]. Figure $3 a, b$ as well as Figure 2a,b shows that the addition of $\mathrm{CaCO}_{3} \mathrm{NPs}$ had no impact on the macroscopic appearances of $5 \%$ and $10 \%$ membranes. A softer and more flexible texture has been found on the $5 \%$ membrane with NPs compared with that of the $10 \%$ membrane with NPs. After incorporated with the $\mathrm{CaCO}_{3} \mathrm{NPs}$, the $5 \%$ and $10 \%$ membranes showed no obvious changes in the fiber morphologies at $5000 \times$ magnification (Figure 3c,d compared with Figure 2c,d). A closer observation at 20,000 $\times$, however, revealed the different positions of the $\mathrm{CaCO}_{3} \mathrm{NPs}$ incorporated with the corresponding fibers. As for the $5 \%$ fibers with NPs (Figure 3e), they had a rougher surface compared to the $5 \%$ fibers without NPs in 
Figure 2e. A similar rough surface was also created on the hydrophobic PAN nanofibers using the same NPs in the literature [27]. A number of fiber fragments with increased diameters (indicated by the red arrows in Figure 3e) emerged after the addition of the NPs, indicating that most of the NPs were covered on the surface of the 5\% PCL nanofibers. Given that the size of the NPs $(50 \mathrm{~nm})$ is comparable to the diameters of the $5 \%$ fibers (averagely $230 \mathrm{~nm}$ showed in Table 1), the surface location of the NPs for $5 \%$ fibers is reasonable. The NPs incorporated in the $10 \%$ fibers, in contrast, aggregated to big clusters and comprised a part of the fibers (Figure 3f). A piece of literature using 12\% PCL solution and a similar amount of $\mathrm{CaCO}_{3}$ NPs showed the same trend to our study with the NPs aggregating in the fibers [26]. A phase separation induced by the poor compatibilities of the hydrophobic fibers and hydrophilic NPs might be explained as the reason.

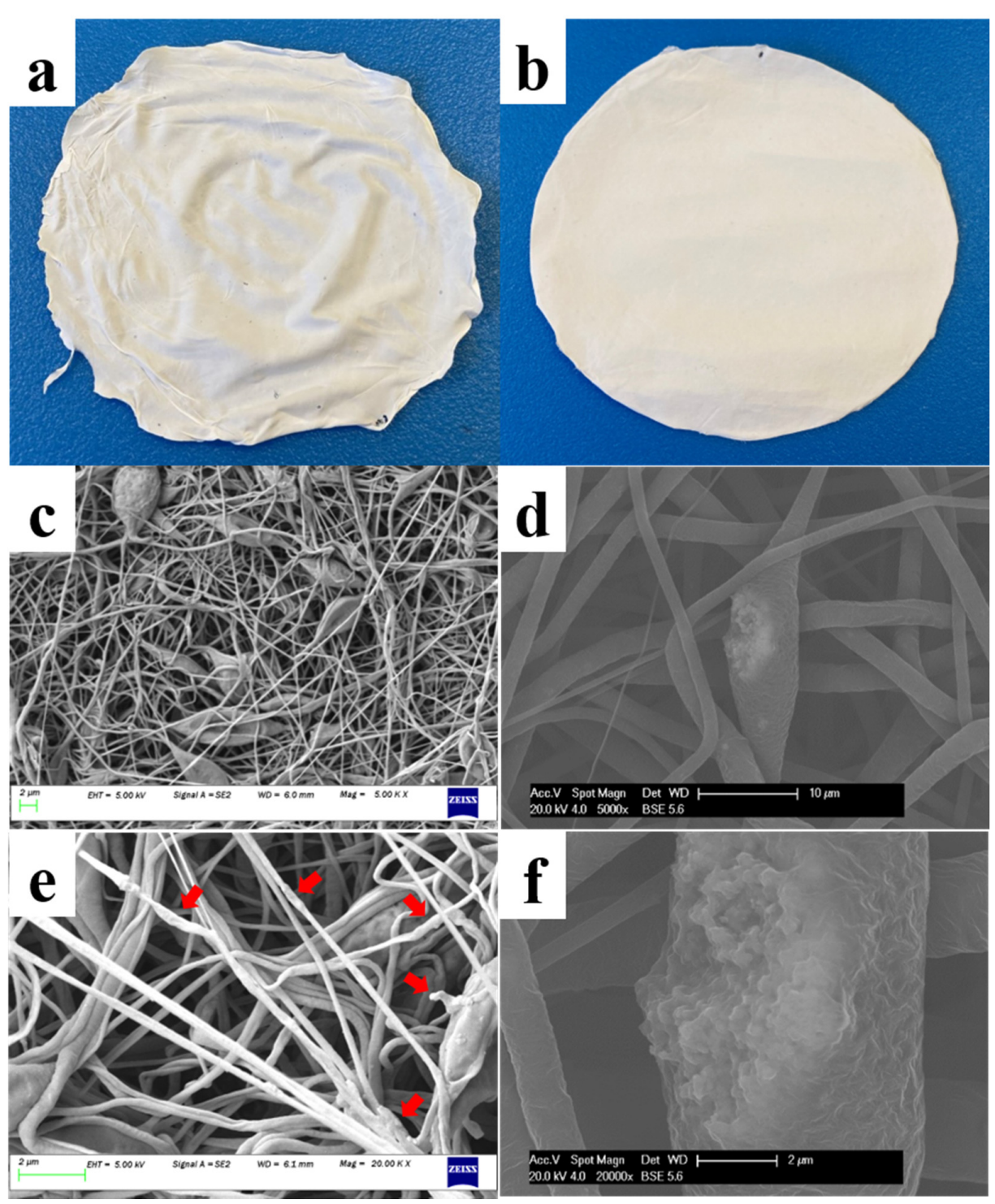

Figure 3. The macroscopic appearances of (a) a 5\% PCL membrane spun with $\mathrm{CaCO}_{3} \mathrm{NPs}_{\text {and }}$ (b) a $10 \%$ PCL membrane spun with $\mathrm{CaCO}_{3}$ NPs. The SEM images of (c) 5\% PCL nanofibers spun with $\mathrm{CaCO}_{3}$ NPs observed at 5000× magnification, (d) $10 \%$ PCL nanofibers spun with $\mathrm{CaCO}_{3}$ NPs observed at $5000 \times$ magnification, (e) 5\% PCL nanofibers spun with $\mathrm{CaCO}_{3}$ NPs at 20,000× magnification, noticing the $\mathrm{CaCO}_{3} \mathrm{NPs}$ covering on some fragments of the fiber surface, (f) a $10 \%$ PCL nanofiber embedded by a cluster of $\mathrm{CaCO}_{3} \mathrm{NPs}$ at $20,000 \times$ magnification. 
Table 1. Physical dimensions of poly ( $\varepsilon$-caprolactone) nanofiber membranes.

\begin{tabular}{ccccc}
\hline Samples & Thickness $(\boldsymbol{\mu m})$ & Fiber Diameter $(\boldsymbol{\mu m})$ & Pore Size $\left(\boldsymbol{\mu \mathbf { m } ^ { 2 }}\right)$ & Porosity $(\%)$ \\
\hline $5 \%$ PCL & $81.3 \pm 6.3$ & $0.23 \pm 0.01$ & $0.91 \pm 0.11$ & $83.0 \pm 0.6$ \\
$10 \%$ PCL & $110.2 \pm 5.9$ & $0.90 \pm 0.06$ & $9.19 \pm 0.89$ & $72.5 \pm 0.5$ \\
\hline
\end{tabular}

\subsection{Membrane Characterization}

The measurement results of thickness, fiber diameter and porosity properties of the $5 \%$ and 10\% PCL membranes have been displayed in Table 1 . The 10\% PCL membranes had an average thickness of $110.2 \mu \mathrm{m}$ and were $35.5 \%$ thicker than the 5\% PCL membranes which had an average thickness of $81.3 \mu \mathrm{m}$. The average fiber diameter and pore size showed a much smaller micro-structure for the membrane made from $5 \% \mathrm{w} / \mathrm{w}$ PCL solution $(0.23 \mu \mathrm{m}$ for fiber diameter and $0.91 \mu^{2}$ for pore size) compared to the membranes made from $10 \%$ $\mathrm{w} / \mathrm{w}$ PCL solution $\left(0.90 \mu \mathrm{m}\right.$ for fiber diameter and $9.19 \mu \mathrm{m}^{2}$ for pore size). The increase in fiber diameter with higher polymer concentration is attributed to the higher stability of polymer jets and the stronger entanglements of the polymer chains induced by more viscous solutions [28]. Larger fibers form larger pore size due to the packing restriction during the fiber deposition process. A linear correlation between fiber diameter and pore size has been reported in the literature [29]. The pore size and fiber diameter of the $10 \%$ membrane measured in this study are consistent with the values reported in the literature using a similar solvent and the same concentration for synthesis $[30,31]$. The porosities of the $5 \%$ and $10 \%$ membranes were $83.0 \%$ and $72.5 \%$, respectively. The data reported here are consistent with the common porosities of PCL membranes in literature which were in a range from $60 \%$ to $90 \%$ [32-34]. This difference in porosity indicates a greater void space in the $5 \%$ membrane compared to that in the $10 \%$ membrane. The result is consistent with the literature [35] showing that the porosity of electrospun scaffold reduced as the diameter of fibers increased.

\subsection{Mechanical Properties of the Membranes}

The tensile properties of the 5\% and 10\% PCL nanofiber membranes spun with or without $\mathrm{CaCO}_{3} \mathrm{NPs}$ were measured in this study using a puncture test. The puncture test is a biaxial test designed to investigate the mechanical behaviors of two-dimensional (flat) materials under plane loading conditions [36]. Compared to a uniaxial tensile test, the puncture test simulated more closely the conditions associated with molecular transport driven by complex multi-loadings vertical to the plane of the membrane.

Figure 4 showed that the puncture strength of the $5 \%$ PCL membrane is $1.02 \mathrm{MPa}$ which is similar to the value of an $8 \%$ PCL membrane (1.2 MPa) reported in the literature [37]. The membrane spun from 5\% PCL solution with 5\% (to the weight of the solute) $\mathrm{CaCO}_{3} \mathrm{NPs}$ was approximately twice as strong as the membrane without NPs $(2.06 \mathrm{MPa}$ compared with $1.02 \mathrm{MPa}$ ), indicating a stronger material created by the addition of the $\mathrm{CaCO}_{3} \mathrm{NPs}$. Likewise, Young's modulus of the $5 \%$ membrane with $\mathrm{CaCO}_{3} \mathrm{NPs}(4.24 \mathrm{MPa})$ was about twice that of the $5 \%$ membrane without NPs (1.92 MPa), which indicates that the addition of the NPs has made the membrane stiffer. The difference in membrane strength and elasticity (Young's modulus) may be due to the $\mathrm{CaCO}_{3}$ NPs covered on the surface of the $5 \%$ nanofibers (Figure $3 \mathrm{e}$ ) which has given additional resistance to the puncture test.

In contrast, the $\mathrm{CaCO}_{3} \mathrm{NPs}$ has made the $10 \%$ membranes weaker and less stiff. The puncture strength of the $10 \%$ PCL membrane without NPs is $2.39 \mathrm{MPa}$ while that of the $10 \%$ membrane with NPs is $1.30 \mathrm{MPa}$ (Figure 4). This result is consistent with the tensile strength of a $10 \%$ PCL membrane reported in the literature being $2.7 \mathrm{MPa}$ [38]. Young's modulus for the $10 \%$ membrane $(7.95 \mathrm{MPa})$ is a little higher than that of the $10 \%$ membrane with NPs (5.49 MPa), indicating a less stiff material has been made by the addition of the NPs. The possible reason for the difference in strength and elasticity (Young's modulus) may be the NP clusters embedded in the fiber bodies in Figure 3d. The clusters might have made the fibers break more readily when being stretched due to the non-stretchable 
property of $\mathrm{CaCO}_{3}$ and the poor compatibility between the hydrophobic PCL and the hydrophilic $\mathrm{CaCO}_{3}$. The remained PCL nanofibers without NP clusters embedded kept the shape of the membrane for the rest of the analysis and produced a comparable elongation property to the membrane without NPs.
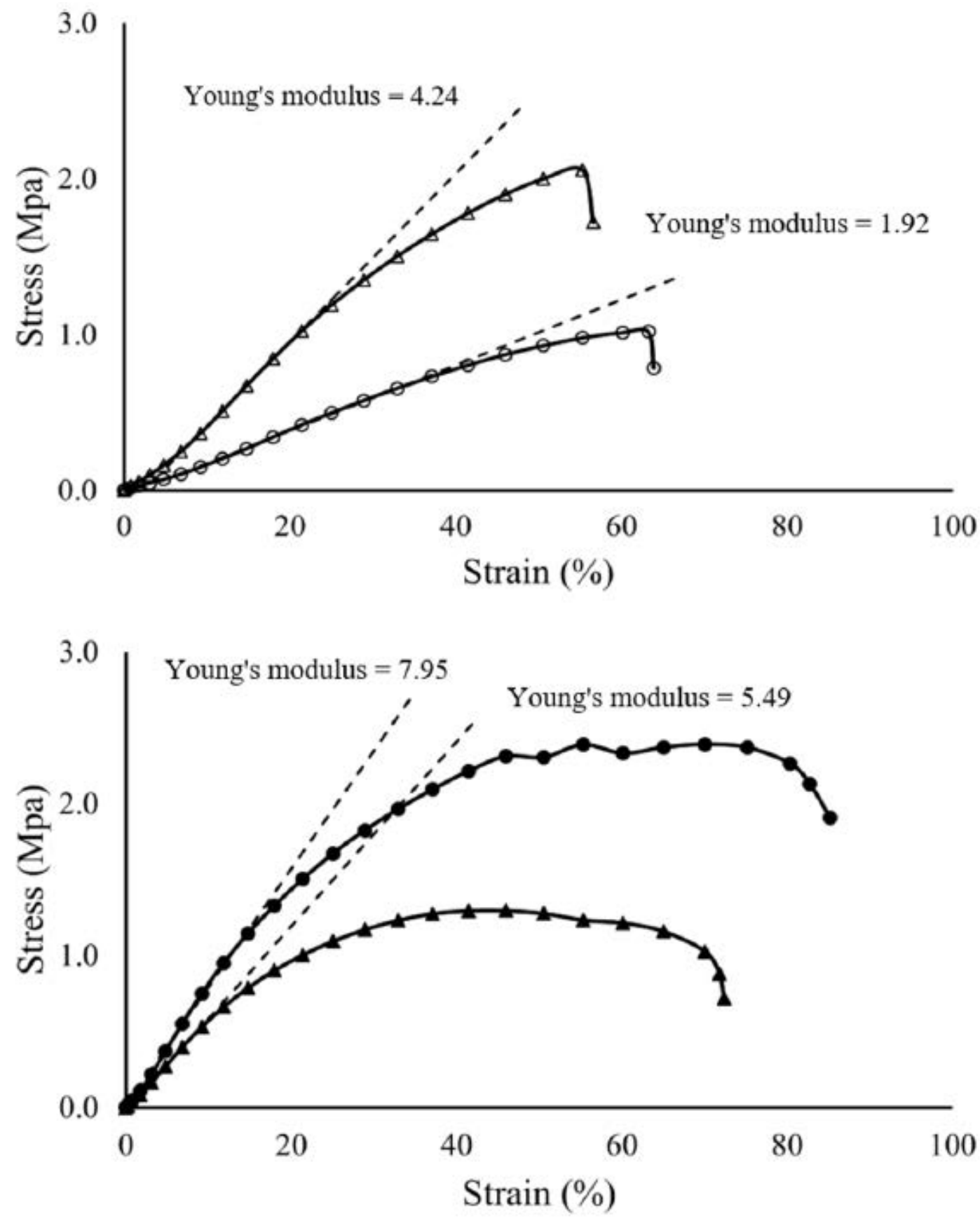

Figure 4. Stress-strain curves $(n=3)$ for: the $5 \%$ PCL membrane $(\bigcirc), 5 \%$ PCL membrane with $\mathrm{CaCO}_{3} \mathrm{NPs}(\triangle), 10 \%$ PCL membrane $(\bullet)$ and $10 \%$ PCL membrane with $\mathrm{CaCO}_{3} \mathrm{NPs}(\boldsymbol{\Delta})$. The dashed lines are the trend of stress growth along with the increase of strain in the linear elastic region, indicating the Young's modulus of each material. 
It has been reported that the tensile strength of electrospun nanofiber membranes is increased as the fiber diameter decreases due to the higher crystallinity and molecular orientation created in thinner fibers $[39,40]$. Our tensile results for the $5 \%$ and $10 \%$ membranes without NPs showed an opposite trend to the previous studies and this was attributed to the formation of micro-beads in the 5\% PCL membrane. Other researchers who tested the strength of their membranes made using a series of polymer concentrations has given a similar result, showing a lower strength in the lower concentration membrane containing micro-beads [41].

\subsection{Contact Angles}

The contact angles of waterdrops were measured for the $5 \%, 5 \%$ with NPs, $10 \%$ and $10 \%$ with NPs membranes. The angles were $131.8^{\circ}, 131.2^{\circ}, 125.1^{\circ}$ and $126.5^{\circ}$, respectively (Figure 5). The contact angles are consistent with the angles reported in the literature [42-44] with a range from $112.4^{\circ}$ to $132.0^{\circ}$ for the spun PCL concentrations from $7.5 \%$ to $12 \%$. A multiple comparison performed using the Tukey method has shown no statistical difference among the 4 contact angles $(p>0.05)$. This result is consistent with the literature where contact angles were reported to be independent of fiber diameters [45]. Unexpectedly the presence of $\mathrm{CaCO}_{3}$ NPs did not affect the hydrophobicity of the PCL membranes. A piece of literature showed that by adding an amount of $\mathrm{CaCO}_{3} \mathrm{NPs}$ up to three times of the weight of spun PCL, there was only a limited contact angle increase [46]. Regarding the tiny amount of $\mathrm{CaCO}_{3} \mathrm{NPs}$ added ( $5 \%$ to the weight of the solute) in this study, this result can be acceptable.

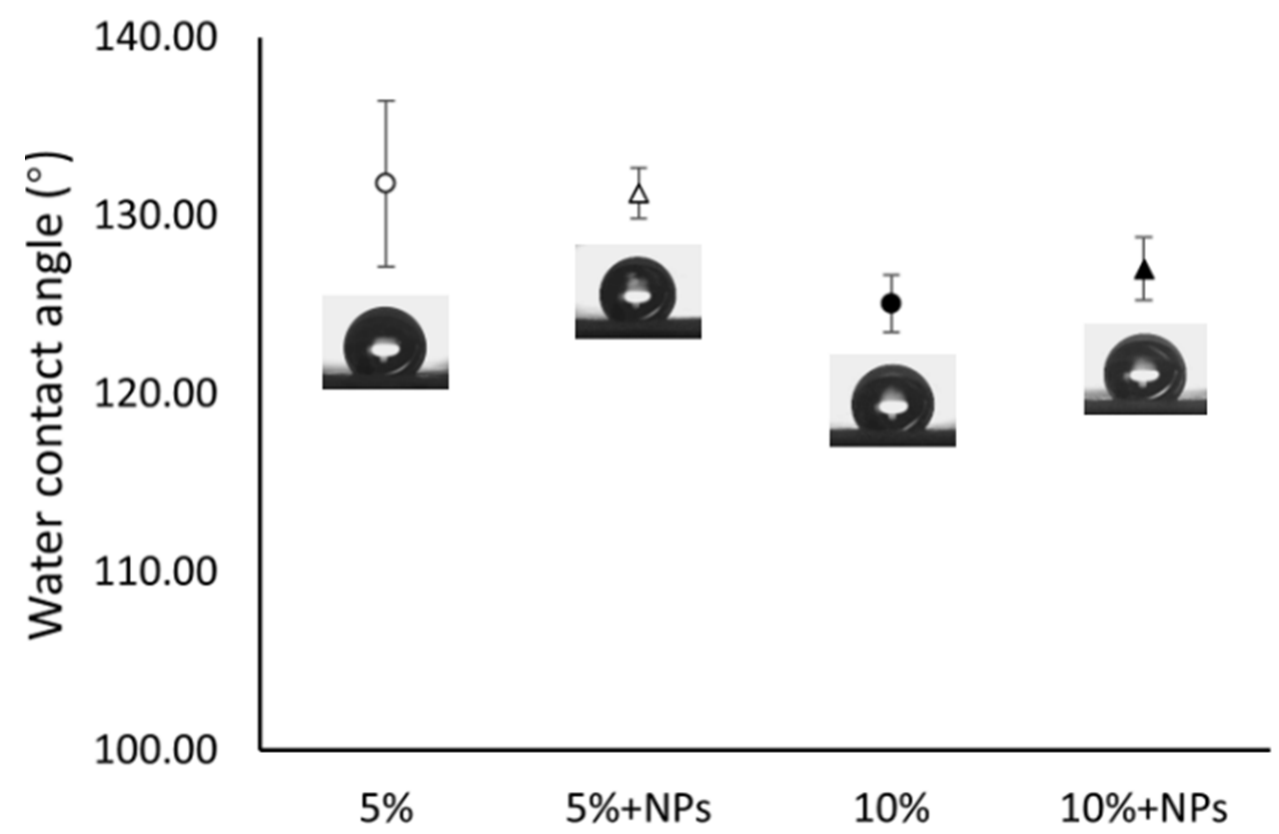

Figure 5. Contact angles of water droplets $(n=3)$ on membranes made using $5 \%$ and $10 \%$ PCL solution with or without NPs. The inserted figures under the error bars are the typical images of the drops on the corresponding nanofiber membranes.

\subsection{Solution Transport Capacity}

Solution transport behaviors across nanofiber membranes were investigated using caffeine as the model drug. Figure 6 shows the caffeine transport through the $5 \%$ and $10 \%$ membranes with or without $\mathrm{CaCO}_{3} \mathrm{NPs}$. The release profiles of the two concentrations differed from each other. Caffeine released through both $10 \%$ membranes with and without NPs from the beginning and showed a decreased release rate with time. In contrast, no caffeine was released during the initial $6 \mathrm{~h}$ for the $5 \%$ membranes with and without NPs, followed by an increased release rate with time. The addition of $\mathrm{CaCO}_{3} \mathrm{NPs}$ was not 
able to change the overall release patterns but contributed to higher release rates in the initial $6 \mathrm{~h}$ for the $10 \%$ membranes and the initial $23 \mathrm{~h}$ for the $5 \%$ membranes. It has been reported that $\mathrm{CaCO}_{3} \mathrm{NPs}$ can be a tool to increase water flux through polymer membranes by increasing their permeability [47]. In our study, the $\mathrm{CaCO}_{3} \mathrm{NPs}$ aided the permeation of water through the membranes at an early period. The Fisher's LSD error bars for the concentrations of caffeine after $6,23,30$ and $48 \mathrm{~h}$ are showed above the solute transport graph. The analysis showed that a significant difference (at a 95\% confidence level) in solute transport between the 5\% membrane and the $10 \%$ membrane as well as between the $5 \%$ membrane and the $10 \%$ membrane with NPs emerged after $23 \mathrm{~h}$ and lasted to the end $(48 \mathrm{~h})$. This result indicates a unique formulation with a solute transport style different from the $10 \%$ membranes with and without NPs has been created using the $5 \%$ membrane.

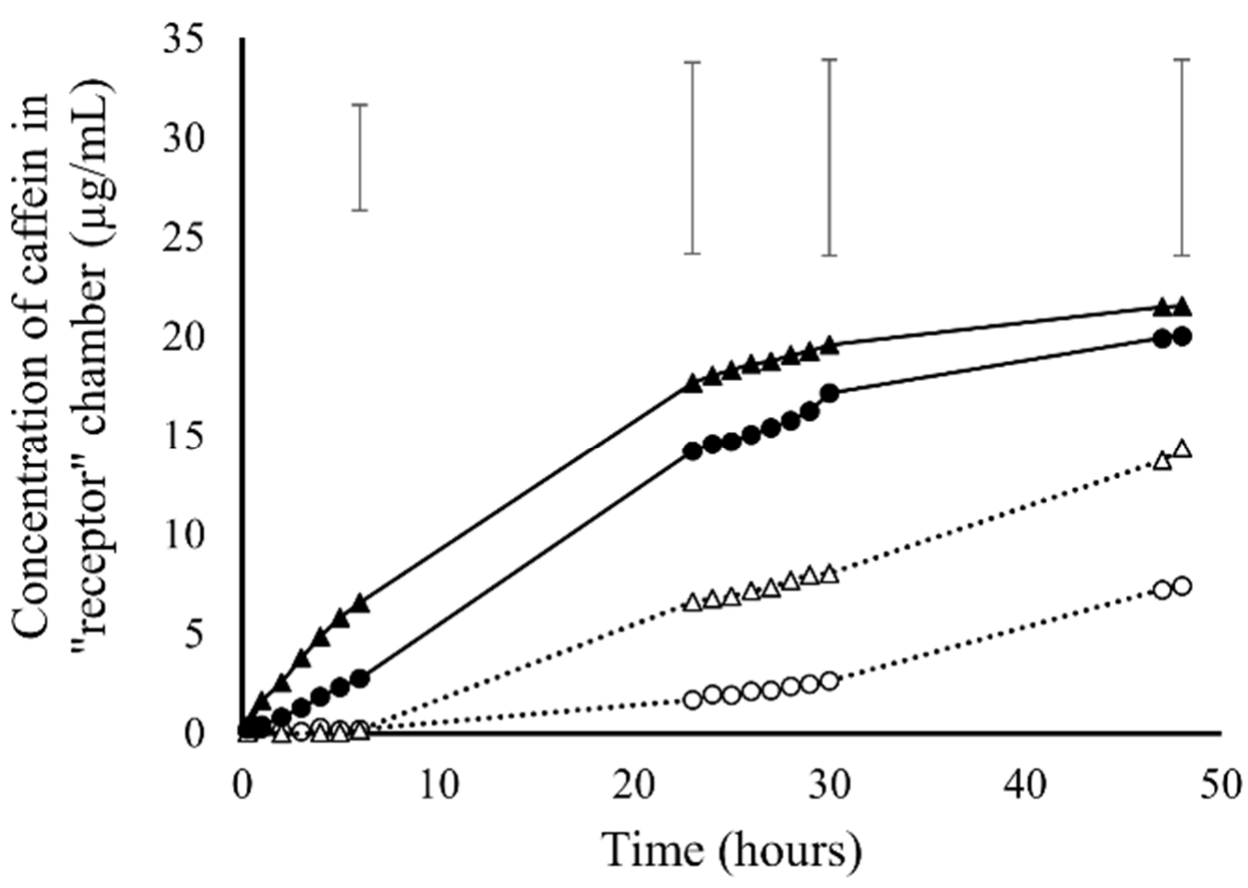

Figure 6. Caffeine transport behaviors $(n=3)$ through the $5 \%$ PCL membrane $(\bigcirc), 5 \%$ PCL membrane with $\mathrm{CaCO}_{3}$ NPs $(\triangle), 10 \%$ PCL membrane $(\bullet)$ and $10 \%$ PCL membrane with $\mathrm{CaCO}_{3}$ NPs $(\boldsymbol{\Delta})$. The error bars are the LSDs for the concentrations of caffeine after 6, 23, 30 and $48 \mathrm{~h}$ at a $95 \%$ confidence level.

Caffeine was selected in this study as the model drug because it has a small molecular size and moderate compatibility to water and organic matter as a partially polar molecule [48,49]. By testing it at a low concentration $(40 \mu \mathrm{g} / \mathrm{mL})$, we are able to eliminate the impact of fouling effect. To confirm no fouling phenomenon existed in this transporting system, the calculated amount of caffeine left in the system after solution samples were extracted out was compared with the measured amount of caffeine left in both "donor" and "receptor" solutions. Figure 7 showed that the measured amounts of caffeine left in solutions were close to the calculated amounts, indicating that all the caffeine molecules dissolved in solution instead of being absorbed or immobilized on the membranes. The difference between measured and calculated amounts are attributed to the loss of water solvent by evaporation during the experimental period. 


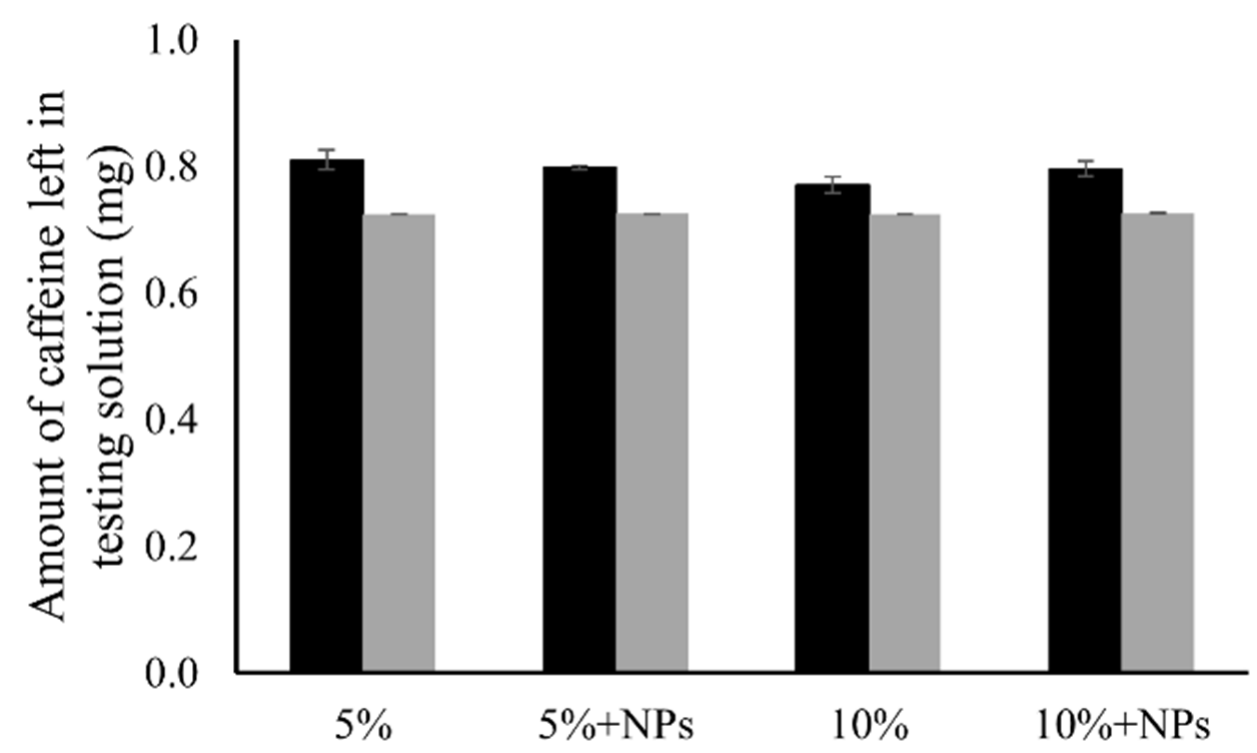

Figure 7. The measured amount $(\square)$ and calculated amount $(\square)$ of caffeine left in the testing solutions after $48 \mathrm{~h}$ test for the 5\% PCL membrane, 5\% PCL membrane with NPs, $10 \%$ PCL membrane and $10 \%$ PCL membrane with NPs.

Based on the membrane characterization results in Sections 3.2 and 3.4 where the impact of thickness and hydrophobicity on release behaviors has been removed, it is believed that the slower release rate of the $5 \%$ membranes is due to the 10-time smaller pore size compared to that of the $10 \%$ membranes $\left(0.91 \mu \mathrm{m}^{2}\right.$ for the $5 \%$ membranes compared with $9.19{\mu \mathrm{m}^{2}}^{2}$ for the $10 \%$ membranes), which has given a higher transporting resistance and created a lower permeability for $5 \%$ membranes. A typical example for the wettability of the $5 \%$ and $10 \%$ membranes after $48 \mathrm{~h}$ transport experiments is shown in Figure 8 where a wetting zone can be seen on the surface of the $10 \%$ membrane (Figure 8a) while no wetting zone can be seen on the surface of the $5 \%$ membrane (Figure $8 b$ ).

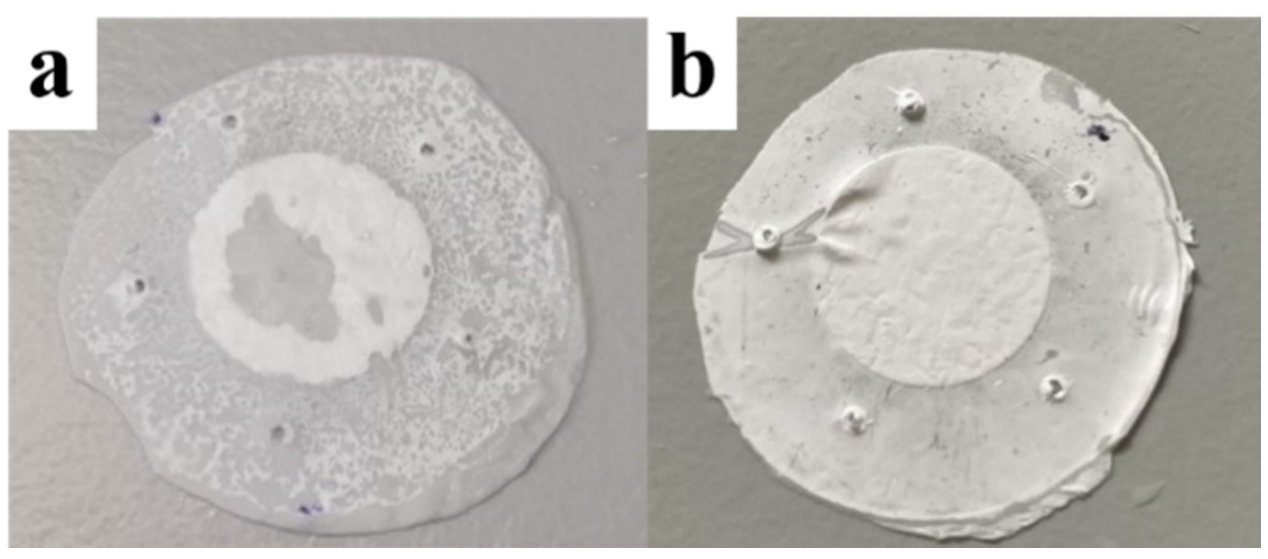

Figure 8. A typical example of a wetted area on the surface of (a) a $10 \%$ membrane and (b) a $5 \%$ membrane after $48 \mathrm{~h}$ solute transport experiments.

Based on all the results, we deduce that the difference in release profile between the $5 \%$ and $10 \%$ membranes resulted from different dominating release mechanisms. Figure 9 demonstrates what has happened on $5 \%$ and $10 \%$ membranes in our presumption. As for the 5\% PCL membranes where wetting of the membranes is difficult, it is presumed that the release rate was increased with the expansion of the permeated areas. This type of release is mainly dominated by the permeability of nanofiber membranes. In contrast, the permeability of the $10 \%$ PCL membranes was so high that there was no significant 
impediment for the transport of the caffeine molecules. The molecules released according to the solute concentration gradient between the two sides of the membrane as the driving force. As the gradient decreased with time, the release rate dropped. This presumption is consistent with our observation in the molecular transport experiments where a positive relationship has been found between the concentration of caffeine in the "receptor" column and the area of wetted zone grown on membrane surface after $48 \mathrm{~h}$. Unfortunately, the images of the wetted areas were not captured. Here, we propose a possible theory based on our understanding. In the same system as this experiment, as the pore size increased, the intrinsic permeability of the membrane increased leading to a transition of release rate from an accelerated style to a decelerated style with time. There should not be a critical value for the transition but a combined role with one driving factor (permeability or concentration gradient) dominating more than another based on the size of micro-structures. The accelerated and decelerated release styles changed with micro-structural dimensions might provide new opportunities for modulated or personalized pharmaceutical designs.

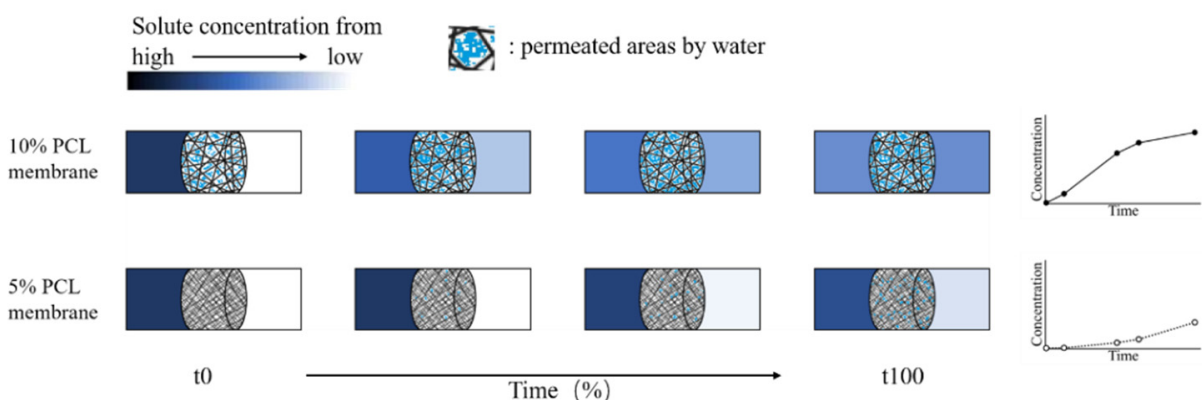

Figure 9. A demonstration of the release mechanisms proposed for the different release profiles for the $5 \%$ and $10 \%$ PCL membranes.

The membranes used in this study were produced under laboratory conditions with a productivity $<1 \mathrm{~g} / \mathrm{h}$. Scale-up would be required for the industrial production of this application. A range of modifications to the conventional stationary one-needle electrospinning have been developed by using multi-needles, a spinneret with multi-holes, air-flow assistance, moving type spinnerets and/or needleless techniques. Productivity of the modified methods up to $450 \mathrm{~g} / \mathrm{h}$ has been reported, which fulfils the requirement of industry [50]. Among the modifications, any approaches that might modify the final composition of the membranes in a detrimental manner should be excluded in order to ensure a controllable structure. This includes, but is not limited to, the use of the free surface method in which the open solution surface to generate multi-jets leads to a change of spun polymer concentration with time due to the escape of volatile solvents over the spinning period [51]. A layer-by-layer formulation is one of the promising designs for this application. Controlled release of carvacrol and $\mathrm{SN}-38$ by sandwiching a drug-containing matrix between two pieces of electrospun membrane has been reported and highlighted the feasibility of the layer-by-layer design [6,7]. Other potential designs, such as using the membranes as a coating for drug tablets, need to be explored and evaluated in future research.

\section{Conclusions}

In this study, we investigated the role of microstructure and the addition of $\mathrm{CaCO}_{3}$ NPs on the molecular release across nanofiber membranes. It has been shown that both the $5 \%$ and $10 \%$ PCL nanofiber membranes can be used as a semi-permeable membrane to control the release of small and water-soluble molecule caffeine. The $5 \%$ membrane with nano-scaled fiber diameter and pore size showed a lower release rate than the $10 \%$ membrane with micro-scaled diameter and pore size. A difference in release profiles of the two membranes indicates different dominating release mechanisms, with membranepermeability controlled release for $5 \%$ membranes resulting in accelerated release rates with time and solute-concentration-gradient controlled release for 10\% membrane resulting 
in decelerated release rates with time. A theory has been proposed by this study that the release profile of solute transporting across nanofiber membranes can be manipulated by altering the size of the microstructure of the nanofiber membranes. It has also been found that $\mathrm{CaCO}_{3} \mathrm{NPs}$ as a hydrophilic filler for the formulations can be used to enhance the permeability of the electrospun membranes and accelerate the initial release of the solute. The NPs, however, impact the mechanical strength and elasticity of the membranes and produced a stronger, stiffer 5\% PCL membrane and a weaker, less stiff 10\% PCL membrane than their counterparts without the NPs. The reduction in structural dimensions and the addition of hydrophilic NPs might be a tool to optimize electrospun membranes for particular uses.

Supplementary Materials: The explanations for the measurement methods of membrane thickness and water contact angle are available online at https://www.mdpi.com/article/10.3390/ pharmaceutics13060916/s1, Figure S1: A photo demonstration of membrane thickness measurement, Figure S2: The schematic diagram of contact angle measurement.

Author Contributions: Conceptualization, W.L. and C.B.; Methodology, W.L. and C.B.; WritingOriginal Draft, W.L.; Writing-Review and Editing, W.L., G.W., S.P., X.Y., J.L. and C.B. All authors have read and agreed to the published version of the manuscript.

Funding: This research was funded by the Ministry of Business, Innovation and Employment "Multifunctional nano-coatings for sustainable agriculture applications" Endeavour Fund Smart Idea (LINX1902); the National Natural Science Foundation of China (NSFC No. 31872177); and the Central Public-interest Scientific Institution Basal Research Fund of Chinese Academy of Agricultural Sciences (No. Y2020XK21). This publication has been partially financed by the Lincoln University Open Access Fund.

Institutional Review Board Statement: Not applicable.

Informed Consent Statement: Not applicable.

Data Availability Statement: The data presented in this study are openly available in Lincoln University at https:/ / doi.org/10.25400/lincolnuninz.14569953.v1 (accessed on 15 May 2021).

Acknowledgments: Bettina Poller, School of Pharmacy, University of Otago, providing SEM analysis; Catherine Hobbis, Research Centre for Surface and Materials Science of University of Auckland, providing SEM analysis.

Conflicts of Interest: The authors declare no conflict of interest. The funders had no role in the design of the study; in the collection, analyses, or interpretation of data; in the writing of the manuscript, or in the decision to publish the results.

\section{References}

1. Bhardwaj, N.; Kundu, S.C. Electrospinning: A fascinating fiber fabrication technique. Biotechnol. Adv. 2010, 28 , 325-347. [CrossRef]

2. Agarwal, S.; Wendorff, J.H.; Greiner, A. Use of electrospinning technique for biomedical applications. Polymer 2008, 49, 5603-5621. [CrossRef]

3. Bhattarai, R.S.; Bachu, R.D.; Boddu, S.H.S.; Bhaduri, S. Biomedical Applications of Electrospun Nanofibers: Drug and Nanoparticle Delivery. Pharmaceutics 2018, 11, 5. [CrossRef]

4. Loh, X.J.; Peh, P.; Liao, S.; Sng, C.; Li, J. Controlled drug release from biodegradable thermoresponsive physical hydrogel nanofibers. J. Control. Release 2010, 143, 175-182. [CrossRef] [PubMed]

5. Yohe, S.T.; Herrera, V.L.M.; Colson, Y.L.; Grinstaff, M.W. 3D superhydrophobic electrospun meshes as reinforcement materials for sustained local drug delivery against colorectal cancer cells. J. Control. Release 2012, 162, 92-101. [CrossRef] [PubMed]

6. Falde, E.J.; Freedman, J.D.; Herrera, V.L.M.; Yohe, S.T.; Colson, Y.L.; Grinstaff, M.W. Layered superhydrophobic meshes for controlled drug release. J. Control. Release 2015, 214, 23-29. [CrossRef]

7. Scaffaro, R.; Maio, A.; Gulino, E.F.; Micale, G.D. PLA-based functionally graded laminates for tunable controlled release of carvacrol obtained by combining electrospinning with solvent casting. React. Funct. Polym. 2020, 148, 104490. [CrossRef]

8. Abdelrasoul, A.; Doan, H.; Lohi, A. Fouling in Membrane Filtration and Remediation Methods. In Mass Transfer-Advances in Sustainable Energy and Environment Oriented Numerical Modeling; IntechOpen: London, UK, 2013. [CrossRef] 
9. Gao, Y.; Haavisto, S.; Li, W.; Tang, C.Y.; Salmela, J.; Fane, A.G.; Chuyang, T. Novel Approach to Characterizing the Growth of a Fouling Layer during Membrane Filtration via Optical Coherence Tomography. Environ. Sci. Technol. 2014, 48, 14273-14281. [CrossRef] [PubMed]

10. Zhao, C.; Si, Y.; Zhu, S.; Bradley, K.; Taha, A.Y.; Pan, T.; Sun, G. Diffusion of Protein Molecules through Microporous Nanofibrous Polyacrylonitrile Membranes. ACS Appl. Polym. Mater. 2021, 3, 1618-1627. [CrossRef]

11. Deitzel, J.M.; Kleinmeyer, J.; Harris, D.; Tan, N.C.B. The effect of processing variables on the morphology of electrospun nanofibers and textiles. Polymer 2001, 42, 261-272. [CrossRef]

12. Chachlioutaki, K.; Tzimtzimis, E.K.; Tzetzis, D.; Chang, M.-W.; Ahmad, Z.; Karavasili, C.; Fatouros, D.G. Electrospun Orodispersible Films of Isoniazid for Pediatric Tuberculosis Treatment. Pharmaceutics 2020, 12, 470. [CrossRef] [PubMed]

13. Mahumane, G.; Kumar, P.; Pillay, V.; Choonara, Y. Repositioning N-Acetylcysteine (NAC): NAC-Loaded Electrospun Drug Delivery Scaffolding for Potential Neural Tissue Engineering Application. Pharmaceutics 2020, 12, 934. [CrossRef]

14. Wang, Z.; Crandall, C.; Sahadevan, R.; Menkhaus, T.J.; Fong, H. Microfiltration performance of electrospun nanofiber membranes with varied fiber diameters and different membrane porosities and thicknesses. Polymer 2017, 114, 64-72. [CrossRef]

15. He, G.; Li, Y.; Li, Z.; Nie, L.; Wu, H.; Yang, X.; Zhao, Y.; Jiang, Z. Enhancing water retention and low-humidity proton conductivity of sulfonated poly(ether ether ketone) composite membrane enabled by the polymer-microcapsules with controllable hydrophilicity-hydrophobicity. J. Power Sources 2014, 248, 951-961. [CrossRef]

16. Maretschek, S.; Greiner, A.; Kissel, T. Electrospun biodegradable nanofiber nonwovens for controlled release of proteins. J. Control. Release 2008, 127, 180-187. [CrossRef]

17. Tawakkal, I.S.; Cran, M.J.; Bigger, S.W. Release of thymol from poly(lactic acid)-based antimicrobial films containing kenaf fibers as natural filler. LWT Food Sci. Technol. 2016, 66, 629-637. [CrossRef]

18. Dwivedi, C.; Pandey, H.; Pandey, A.C.; Patil, S.; Ramteke, P.W.; Laux, P.; Luch, A.; Singh, A.V. In Vivo Biocompatibility of Electrospun Biodegradable Dual Carrier (Antibiotic + Growth Factor) in a Mouse Model-Implications for Rapid Wound Healing. Pharmaceutics 2019, 11, 180. [CrossRef] [PubMed]

19. Simões, M.C.R.; Cragg, S.M.; Barbu, E.; De Sousa, F.B. The potential of electrospun poly(methyl methacrylate)/polycaprolactone core-sheath fibers for drug delivery applications. J. Mater. Sci. 2018, 54, 5712-5725. [CrossRef]

20. Jovanović, M.; Tomić, N.; Cvijić, S.; Stojanović, D.; Ibrić, S.; Uskoković, P. Mucoadhesive Gelatin Buccal Films with Propranolol Hydrochloride: Evaluation of Mechanical, Mucoadhesive, and Biopharmaceutical Properties. Pharmaceutics 2021, $13,273$. [CrossRef]

21. Williamsa, D.L.; Kuhnb, A.T.; Amanna, M.A.; Hausingera, M.B.; Konarika, M.M.; Nesselrodea, E.I. Computerised measurement of contact angles. Galvanotechnik 2010, 10, 1-11.

22. Haghi, A.K.; Akbari, M. Trends in electrospinning of natural nanofibers. Phys. Status Solidi A 2007, 204, 1830-1834. [CrossRef]

23. Haider, A.; Haider, S.; Kang, I.-K. A comprehensive review summarizing the effect of electrospinning parameters and potential applications of nanofibers in biomedical and biotechnology. Arab. J. Chem. 2018, 11, 1165-1188. [CrossRef]

24. Mehraban, M.; Zadhoush, A.; Ravandi, S.A.H.; Bagheri, R.; Tehrani, A.H. Preparation of porous nanofibers from electrospun polyacrylonitrile/calcium carbonate composite nanofibers using porogen leaching technique. J. Appl. Polym. Sci. 2013, 128, 926-933. [CrossRef]

25. Wang, Y.; Wang, B.; Wang, G.; Yin, T.; Yu, Q. A novel method for preparing electrospun fibers with nano-/micro-scale porous structures. Polym. Bull. 2009, 63, 259-265. [CrossRef]

26. Wutticharoenmongkol, P.; Sanchavanakit, N.; Pavasant, P.; Supaphol, P. Preparation and Characterization of Novel Bone Scaffolds Based on Electrospun Polycaprolactone Fibers Filled with Nanoparticles. Macromol. Biosci. 2006, 6, 70-77. [CrossRef] [PubMed]

27. Liu, H.; Cao, C.-Y.; Wei, F.-F.; Jiang, Y.; Sun, Y.-B.; Huang, P.-P.; Song, W.-G. Fabrication of Macroporous/Mesoporous Carbon Nanofiber Using CaCO3 Nanoparticles as Dual Purpose Template and Its Application as Catalyst Support. J. Phys. Chem. C 2013, 117, 21426-21432. [CrossRef]

28. Matabola, K.P.; Moutloali, R.M. The influence of electrospinning parameters on the morphology and diameter of poly(vinyledene fluoride) nanofibers-effect of sodium chloride. J. Mater. Sci. 2013, 48, 5475-5482. [CrossRef]

29. Lowery, J.L.; Datta, N.; Rutledge, G.C. Effect of fiber diameter, pore size and seeding method on growth of human dermal fibroblasts in electrospun poly( $\varepsilon$-caprolactone) fibrous mats. Biomaterials 2010, 31, 491-504. [CrossRef]

30. Dikici, B.A.; Dikici, S.; Reilly, G.C.; MacNeil, S.; Claeyssens, F. A Novel Bilayer Polycaprolactone Membrane for Guided Bone Regeneration: Combining Electrospinning and Emulsion Templating. Materials 2019, 12, 2643. [CrossRef]

31. Doergens, A.; Roether, J.A.; Dippold, D.; Boccaccini, A.R.; Schubert, D.W. Identifying key processing parameters for the electrospinning of aligned polymer nanofibers. Mater. Lett. 2015, 140, 99-102. [CrossRef]

32. Chakrapani, V.Y.; Gnanamani, A.; Giridev, V.; Madhusoothanan, M.; Sekaran, G. Electrospinning of type I collagen and PCL nanofibers using acetic acid. J. Appl. Polym. Sci. 2012, 125, 3221-3227. [CrossRef]

33. Hassan, A.A.; Radwan, H.A.; Abdelaal, S.A.; Al-Radadi, N.S.; Ahmed, M.K.; Shoueir, K.R.; Hady, M.A. Polycaprolactone based electrospun matrices loaded with Ag/hydroxyapatite as wound dressings: Morphology, cell adhesion, and antibacterial activity. Int. J. Pharm. 2021, 593, 120143. [CrossRef]

34. Ajmal, G.; Bonde, G.V.; Mittal, P.; Khan, G.; Pandey, V.K.; Bakade, B.V.; Mishra, B. Biomimetic PCL-gelatin based nanofibers loaded with ciprofloxacin hydrochloride and quercetin: A potential antibacterial and anti-oxidant dressing material for accelerated healing of a full thickness wound. Int. J. Pharm. 2019, 567, 118480. [CrossRef] 
35. Soliman, S.; Sant, S.; Nichol, J.W.; Khabiry, M.; Traversa, E.; Khademhosseini, A. Controlling the porosity of fibrous scaffolds by modulating the fiber diameter and packing density. J. Biomed. Mater. Res. Part A 2011, 96, 566-574. [CrossRef] [PubMed]

36. Chen, H.-X.; Liu, X.; Feng, S.-J.; Chen, J.-N.; Zhang, D.-M.; Zhou, A. Microscale investigation into mechanical behaviors of heat-bonded nonwoven geotextile using DEM. Geotext. Geomembranes 2019, 47, 429-438. [CrossRef]

37. Costa, L.M.M.; Mattoso, L.H.C.; Ferreira, M. Electrospinning of PCL/natural rubber blends. J. Mater. Sci. 2013, 48, 8501-8508. [CrossRef]

38. Zhang, Y.; Ouyang, H.; Lim, C.T.; Ramakrishna, S.; Huang, Z.-M. Electrospinning of gelatin fibers and gelatin/PCL composite fibrous scaffolds. J. Biomed. Mater. Res. Part B Appl. Biomater. 2004, 72, 156-165. [CrossRef]

39. Wong, S.-C.; Baji, A.; Leng, S. Effect of fiber diameter on tensile properties of electrospun poly(E-caprolactone). Polymer 2008, 49, 4713-4722. [CrossRef]

40. Chinatangkul, N.; Tubtimsri, S.; Panchapornpon, D.; Akkaramongkolporn, P.; Limmatvapirat, C.; Limmatvapirat, S. Design and characterisation of electrospun shellac-polyvinylpyrrolidone blended micro/nanofibers loaded with monolaurin for application in wound healing. Int. J. Pharm. 2019, 562, 258-270. [CrossRef] [PubMed]

41. Huang, Z.-M.; Zhang, Y.; Ramakrishna, S.; Lim, C. Electrospinning and mechanical characterization of gelatin nanofibers. Polymer 2004, 45, 5361-5368. [CrossRef]

42. Hassan, M.I.; Sultana, N. Characterization, drug loading and antibacterial activity of nanohydroxyapatite/polycaprolactone (nHA/PCL) electrospun membrane. 3 Biotech 2017, 7, 249. [CrossRef] [PubMed]

43. Metwally, S.; Karbowniczek, J.E.; Szewczyk, P.K.; Marzec, M.M.; Gruszczyński, A.; Bernasik, A.; Stachewicz, U. Single-Step Approach to Tailor Surface Chemistry and Potential on Electrospun PCL Fibers for Tissue Engineering Application. Adv. Mater. Interfaces 2019, 6, 1801211. [CrossRef]

44. Pant, H.R.; Neupane, M.P.; Pant, B.; Panthi, G.; Oh, H.-J.; Lee, M.H.; Kim, H.Y. Fabrication of highly porous poly ( $\varepsilon$-caprolactone) fibers for novel tissue scaffold via water-bath electrospinning. Colloids Surf. B Biointerfaces 2011, 88, 587-592. [CrossRef]

45. Szewczyk, P.K.; Ura, D.P.; Metwally, S.; Knapczyk-Korczak, J.; Gajek, M.; Marzec, M.M.; Bernasik, A.; Stachewicz, U. Roughness and Fiber Fraction Dominated Wetting of Electrospun Fiber-Based Porous Meshes. Polymers 2018, 11, 34. [CrossRef] [PubMed]

46. Park, J.-Y.; Kyung, K.-H.; Tsukada, K.; Kim, S.-H.; Shiratori, S. Biodegradable polycaprolactone nanofibers with $\beta$-chitosan and calcium carbonate produce a hemostatic effect. Polymer 2017, 123, 194-202. [CrossRef]

47. Saki, S.; Uzal, N. Preparation and characterization of PSF/PEI/CaCO3 nanocomposite membranes for oil/water separation. Environ. Sci. Pollut. Res. 2018, 25, 25315-25326. [CrossRef] [PubMed]

48. Maynard, R.L. The Merck index. Occup. Environ. Med. 1996, 12, 1-288.

49. Prankerd, R.J. Critical Compilation of pKa Values for Pharmaceutical Substances. Profiles Drug Subst. Excip. Relat. Methodol. 2007, 33, 1-33. [CrossRef]

50. Vass, P.; Szabó, E.; Domokos, A.; Hirsch, E.; Galata, D.; Farkas, B.; Démuth, B.; Andersen, S.K.; Vigh, T.; Verreck, G.; et al. Scale-up of electrospinning technology: Applications in the pharmaceutical industry. Wiley Interdiscip. Rev. Nanomed. Nanobiotechnology 2020, 12, e1611. [CrossRef]

51. Wei, L.; Sun, R.; Liu, C.; Xiong, J.; Qin, X. Mass production of nanofibers from needleless electrospinning by a novel annular spinneret. Mater. Des. 2019, 179, 107885. [CrossRef] 